\title{
A ESTÉTICA E A DISCUSSÃo SOBRE INDÚSTRIA CULTURAL NO BRASIL
}

Rodrigo Duarte*

Assim como, a partir do início do século XX, houve na filosofia da arte europeia uma tendência à superação das discussões mais abstratas que tinham como objeto a arte "autônoma", no sentido tradicional do termo, em direção às tentativas de compreensão dos novos fenômenos estéticos oriundos da recém-surgida cultura de massas, pode-se observar - com uma defasagem maior ou menor, conforme o caso - um movimento análogo nas considerações congêneres realizadas no Brasil, desde as primeiras décadas do século passado até hoje. Para abordar, ainda que de modo muito incipiente e incompleto, esse interessante desenvolvimento na história cultural do país, adota-se aqui como estratégia, primeiramente, relembrar alguns pontos de inflexão do processo ocorrido na estética europeia, para depois introduzir alguns elementos imprescindíveis na discussão da indústria cultural no Brasil, tendo como pano de fundo os aportes da estética filosófica tradicional, os quais revelam-se indispensáveis para a manutenção do ponto de vista crítico.

* Doutor pela Universität Gesamthochschule Kassel (Alemanha), professor titular do Departamento de Filosofia da Universidade Federal de Minas Gerais (UFMG), pesquisador do CNPq e presidente da Associação Brasileira de Estética. E-mail: roduarte@fafich.ufmg.br. 
$|74|$

A estética e a discussão sobre indústria cultural no Brasil..

\section{Da autonomia da arte à heteronomia do produto cultural}

Embora as indagações filosóficas sobre a arte remontem à Antiguidade clássica, a Modernidade europeia, especialmente a partir do século XVIII, foi responsável por um novo e importante impulso nesse campo, legando à posteridade, inclusive, o termo "estética" - cunhado por Baumgarten em 1750 (cf. ed. bras.: Von Baumgarten, 1993) -, que é hoje correntemente utilizado.

É interessante observar que, a partir do início do settecento iniciaram-se na França e na Inglaterra (posteriormente também na Alemanha) discussões sobre o tema da imitação, tanto no sentido de a arte - inclusive a poesia - ser ou não mímesis da natureza, quanto no de as artes da época terem ou não que obrigatoriamente imitar as da Antiguidade, consideradas por muitos insuperáveis (isso constituiu parte da famosa "querela dos antigos e modernos").

Toda essa discussão, na qual temas já surgidos na Antiguidade (como o da supramencionada mímesis, do sublime e do estilo) se enriqueciam com outros mais tipicamente modernos (como o da autonomia da arte, por exemplo), desembocou numa obra, que, mesmo não abordando exclusivamente essa temática, acabou se constituindo no fundamento da estética moderna. Trata-se da Crítica da faculdade do juízo, de Immanuel Kant, que teve sua primeira edição publicada em 1790.

Nessa obra, Kant parte da especificidade do que ele chama de "juízo de gosto" - o juízo sobre o belo -, o qual se distingue do juízo de conhecimento (ou "lógico") pelo fato de que, nele, não se atribui um predicado a um sujeito, resumindo-se o ajuizamento ao "prazer desinteressado" que o sujeito constata no seu ânimo, na presença de um objeto com características peculiares:

O juízo do gosto não é, pois, nenhum juízo de conhecimento, por conseguinte não é lógico e sim estético, pelo qual se entende aquilo cujo fundamento de determinação não pode ser senão subjetivo. Toda referência das representações, mesmo a das sensações, pode, porém, ser objetiva (e ela significa 
então o real de uma representação empírica); somente não pode sê-lo a referência ao sentimento de prazer e desprazer, pelo qual não é designado absolutamente nada no objeto, mas no qual o sujeito sente-se a si próprio do modo como ele é afetado pela sensação (Kant, 1984, p. 115). ${ }^{1}$

O fato de o prazer que ele sente não ser acompanhado de qualquer interesse, i.e., de desejo de possuir o objeto, implica numa segunda qualidade específica (e desconcertante) do juízo de gosto, que é o fato de ele dever ser considerado "universal", apesar de ocorrer tão somente na consciência de quem contempla aquela coisa a ser possivelmente considerada bela. A explicação que Kant dá para isso é o fato de esse juízo ser universal apenas no sentido "estético" e não no sentido "lógico" (no de um juízo de conhecimento). Essa universalidade estética implica em que seja lícito esperar que, potencialmente, qualquer pessoa possa assentir no juízo sobre a beleza de um objeto, desde que ele cumpra os requisitos supramencionados.

O fato de o juízo de gosto não ser lógico, implica, dentre outras coisas, que ele seja desprovido de conceito, o que, por sua vez, faz com que o seu objeto seja percebido como uma finalidade apenas formal. Isso significa que há, tendo em vista a harmonia de sua forma, a insinuação de uma finalidade nesse objeto, a qual não permite, entretanto, a explicitação de qualquer fim - propósito - específico para ele.

Na prática, as características que Kant atribui ao juízo de gosto - e, por extensão, ao seu objeto - significam que, para ser considerada bela, uma coisa deve despertar no seu contemplador um prazer desvinculado da posse, sendo que isso é uma decorrência do fato de sua forma sugerir finalidade sem explicitar fins (i.e., a coisa não tem uma utilidade imediata). Por outro lado, esse prazer é tido por Kant como "universal" e "necessário", o que aponta para o fato de virtualmente toda a humanidade

\footnotetext{
${ }^{1}$ Para essa citação foi usada a tradução de Rohden e Marques, 1995, p. 48.
} 
$|76|$

A estética e a discussão sobre indústria cultural no Brasil...

secundar o prazer desinteressado sentido por seu contemplador ao perceber o objeto candidato ao título de "belo":

Todo fim, se é considerado como fundamento da complacência, comporta sempre um interesse como fundamento de determinação do juízo sobre o objeto do prazer. Logo, não pode haver nenhum fim subjetivo como fundamento do juízo de gosto. Mas também nenhuma representação de um fim objetivo, isto é, da possibilidade do próprio objeto segundo princípios da ligação a fins, por conseguinte nenhum conceito de bom pode determinar o juízo de gosto; porque ele é um juízo estético e não um juízo de conhecimento, o qual, pois, não concerne a nenhum conceito da natureza e da possibilidade interna ou externa do objeto através desta ou daquela causa, mas simplesmente à relação das faculdades de representação entre si, na medida em que elas são determinadas por uma representação (Kant, 1995, p. 66 ss.)

Kant procede de modo aproximadamente análogo em relação ao sublime - outro conceito fundamental da estética moderna -, no sentido de desvinculá-lo de sentimentos estéticos "empíricos", i.e., dependentes de um agrado imediato dos sentidos, que possam implicar no imediato desejo de posse e de consumo do objeto que ocasiona o prazer (fazendo com que ele seja, nesse caso, interessado). Mas, por motivo de economia da exposição, não tratarei, aqui, do sublime, já que mutatis mutandis, o que se disse sobre o juízo de gosto, no tocante ao tema da "autonomia da arte", vale também para o juízo sobre o sublime.

Muita coisa aconteceu na estética europeia depois de Kant: Hegel releu - e, de certo modo, relativizou - a ideia de "autonomia da arte", enquadrando-a numa dialética histórica das formas artísticas. Essa dialética foi recolocada por Marx em termos de dependência da superestrutura ideológica (na qual se encontraria a arte) com relação à infraestrutura econômica da sociedade, mesmo que essa vinculação não possa ser considerada mecânica. 
Nietzsche, por sua vez, estendeu o modelo da arte autônoma para o âmbito de toda a vida humana, procurando erigir a dimensão estética em referencial inclusive para as suas atividades morais e gnosiológicas:

\begin{abstract}
Pois entre duas esferas absolutamente diferentes como sujeito e objeto, não há qualquer causalidade, qualquer correção, qualquer expressão, porém no máximo um procedimento estético, quero dizer, uma transposição alusiva, uma tradução balbuciante numa linguagem totalmente estranha, para a qual precisa-se de qualquer modo de uma esfera e de uma força intermediárias livremente poetantes e inventivas (Nietzsche, 1979, p. 317, tradução do autor).
\end{abstract}

Heidegger prosseguiu cum grano salis nesse caminho, na medida em que procurou traduzir a proximidade existencial da arte com relação à vida, refletida por Nietzsche, em termos propriamente ontológicos, i.e., tornando as obras de arte propriamente ditas como verdadeiras aberturas de clareiras nas florestas dos entes, na quais há a possibilidade de manifestação do próprio ser.

E claro que os movimentos feitos pela filosofia do final do século XIX e início do XX foram no sentido de relativizar a concepção mais radical de autonomia da arte que se desenvolveu a partir do Renascimento e teve sua resposta filosófica mais completa, como se sugeriu acima, com a Crítica da faculdade do juízo de Kant. Mas, de qualquer modo, dificilmente alguma virada nesse sentido se compara àquela inaugurada por Max Horkheimer e Theodor Adorno, na sua obra publicada em 1947, Dialética do esclarecimento. Nela, os autores, apesar de continuarem acreditando que ainda haveria espaço para a existência de "arte autônoma", procuram dar conta filosófica do surgimento de algo totalmente novo no cenário da produção de construtos estéticos, a saber, aquilo que ficou conhecido como "cultura de massas".

Nela, os padrões aceitos durante quase dois séculos da "arte autônoma" caem por terra, na medida em que, desde o início, 
$|78|$

A estética e a discussão sobre indústria cultural no Brasil...

esses construtos eram fruto de produção realizada sob medida para o consumo das multidões - principalmente operárias - que superlotavam as metrópoles europeias e norte-americanas, nas primeiras décadas do século XX. Com isso, a espontaneidade que caracterizara a arte propriamente dita não existia mais, embora esses construtos devessem parecer o mais espontâneos possível para satisfazer a demanda por entretenimento das massas urbanas dos países mais industrializados da época.

Uma importante novidade nessa primeira abordagem filosófica da "cultura de massas" é que Horkheimer \& Adorno rejeitaram esse termo, sob a alegação de que ele poderia sugerir uma cultura feita pelas massas para consumo próprio, quando o que estava em questão era o advento de um poderoso setor fabril, no qual a produção de construtos estéticos deveria conciliar demandas explícitas do público por entretenimento com necessidades imediatas de lucratividade e - last but not least - com a possibilidade de controle ideológico das massas que se mostravam propensas à adesão a pontos de vista antagônicos ao capitalismo recém entrado na sua fase monopolista (sindicalismo socialista, anarquismo, etc.).

Um dos expedientes utilizados pelo então incipiente ramo da economia para atingir essa conciliação foi tentar perscrutar os anseios latentes das massas e oferecer produtos que atendessem a essa demanda não explícita de modo a garantir tanto o seu lucro daquele dia quanto o dos dias vindouros, i.e., na medida em que a ideologia do capitalismo tardio não fosse tocada. Pelo contrário, ela deveria ser reforçada no nível das necessidades libidinais dos indivíduos componentes dessas massas (não foi à toa que a chamada "Escola de Frankfurt" foi uma das primeiras vertentes filosóficas a aproximar Marx de Freud) sem que isso lhes fosse evidente: elas "escolhiam" o que interessava antes de tudo ao sistema econômico e ideológico, achando que a escolha era espontaneamente sua.

Para designar esse importante fenômeno do início do século XX nos países capitalistas mais desenvolvidos, Horkheimer \& Adorno cunharam o termo "Indústria cultural", que, na época, 
deve ter soado muito estranho. De acordo com os padrões vigentes até um pouco antes, esse termo seria um oximoro, pois, na concepção anterior sobre os fenômenos estéticos (influenciadas pelo ponto de vista de Kant e de seus pósteros mais imediatos), se algo era industrial, não podia ser cultural; se era cultural, não podia ser industrial. Numa referência direta à Crítica da faculdade do juízo, Horkheimer e Adorno declaram que,

O princípio da estética idealista, a finalidade sem fim, é a inversão do esquema a que obedece socialmente a arte burguesa: a falta de finalidade para os fins determinados pelo mercado. (...) O que se poderia chamar de valor de uso na recepção dos bens culturais é substituído pelo valor de troca; ao invés do prazer, o que se busca é assistir e estar informado, o que se quer é conquistar prestígio e não se tornar um conhecedor (...) O valor de uso da arte, seu ser, é considerado como um fetiche, e o fetiche, a avaliação social que é erroneamente entendida como hierarquia das obras de arte - torna-se seu único valor de uso, a única qualidade que elas desfrutam (Horkheimer e Adorno, 1981, p. 181 ss.). ${ }^{2}$

É interessante observar que, mesmo antes da redação e da publicação da Dialética do esclarecimento, um dos primeiros debates propriamente filosóficos sobre temas afeitos à cultura de massas ocorreu entre Theodor Adorno e seu amigo Walter Benjamin, a saber, sobre o papel da chamada "reprodutibilidade técnica" da obra de arte. Como é amplamente sabido, Benjamin defendeu no seu ensaio $A$ obra de arte na era de sua reprodutibilidade técnica a ideia de que a arte tradicional estaria com os dias contados, já que os novos meios reprodutíveis como a fotografia e o cinema tomariam o seu lugar inclusive quanto à possibilidade de emancipação das massas da tutela das classes dominantes. Adorno, sem negar

${ }^{2}$ Para essa citação, foi usada a tradução de Almeida, 1985, p. 148. 
|80|

A estética e a discussão sobre indústria cultural no Brasil...

a realidade e a grande influência dos meios de massa, insistia no ponto de vista de que a arte convencional, "burguesa", apesar de ter sua própria existência ameaçada pela indústria cultural, seria insubstituível como balizamento crítico, tanto da produção daquela época quanto da que estaria por vir. Hoje, a uma distância histórica considerável, é possível afirmar que o potencial emancipador que Benjamin vira na "arte reprodutível" não se desenvolveu na medida necessária, firmando-se a cultura de massas muito mais como entretenimento e - lucrativa manipulação ideológica do que como trampolim para a libertação do gênero humano. E Benjamin, que em outros textos da mesma época do ensaio sobre a reprodutibilidade técnica defendera um ponto de vista bem próximo do de Adorno, é hoje - de modo não totalmente justo - tomado como apologeta da indústria cultural e inclusive reverenciado por muitos exatamente por isso.

De qualquer modo, é oportuno observar que, já na época em que o conceito de "indústria cultural" foi desenvolvido, os media predominantes eram o complexo rádio/indústria fonográfica e o cinema, complementados pelas revistas ilustradas. E esse tripé, plenamente funcional nos Estados Unidos, já na década de 1920, garantiu a adesão das massas ao projeto expansionista norteamericano no entre guerras, à própria participação desse país na $2^{a}$ Grande Guerra (se bem que, nesse caso, justificadamente, já que se tratava de derrotar o nazismo) e à difusão do american way of life no pós-guerra como padrão de comportamento por todo o mundo ocidental e adjacências. Isso não impediu, entretanto, que tais media fossem passando por transformações, tanto no sentido de se adequar melhor às suas funções quanto no de acompanhar desenvolvimentos tecnológicos que resultaram, por exemplo, na adoção da TV como principal medium da indústria cultural e na incorporação de meios mais "interativos" - primeiramente analógicos como cassetes de áudio e de vídeo (a partir da década de 1970) e depois digitais (a partir da década de 1990), como todos os recursos audiovisuais e gráficos postos à disposição do público atualmente. 
É interessante considerar que essa "interatividade", que atingiu o seu ápice com os atuais media digitais, em que pese sua maior flexibilidade e até mesmo o seu potencial emancipatório e crítico - porque criativo -, nada mudou quanto à estrutura econômica e o comportamento político-ideológico das instâncias de produção da indústria cultural, de modo que o seu poder de coerção permanece praticamente o mesmo do que era no era no início da década de 1920, tendo apenas se adaptado às transformações tecnológicas e às novas situações geopolíticas, como, por exemplo, a chamada "globalização", que nada mais foi (e é) que a universalização do capitalismo na sua modalidade não concorrencial ou monopolista (talvez oligopolista, para ser mais exato).

Essas posições se ligam a um debate mais recente sobre a cultura de massas, iniciado no final dos anos 1990, que teve como fulcro temático o que se chamou de "indústria cultural global". Já que esse debate teve reflexos interessantes em discussões realizadas também no Brasil, parece-me oportuno passar à abordagem da flexão que o tema teve entre nós, não sem antes enfocar brevemente o cenário dos enfoques mais gerais sobre estética que emolduraram aquelas discussões.

\section{Brasil: Da estética acadêmica aos debates sobre a cultura de} massas

Para fazer um caminho paralelo, na discussão da situação brasileira, ao realizado na abordagem sobre a filosofia da arte em geral, na Europa do settecento, para chegar ao tema da indústria cultural (especialmente nos Estados Unidos do novecento), seria interessante relembrar os primórdios da estética no Brasil. Ao que consta, a primeira vez que o termo apareceu no conteúdo de uma obra foi nas Preleções Philosophicas sobre a theorica do discurso e da linguagem, a esthetica, a diceosyna e a cosmologia, de Silvestre Pinheiro Ferreira (Rio de Janeiro: Na impressão Regia, 1813). Ainda no século XIX, foi publicado também o livro Questões 
$|82|$

A estética e a discussão sobre indústria cultural no Brasil...

de arte, de Carlo Parlagreco (Rio de Janeiro, Companhia Tipográfica do Brasil, 1895). Já no início do século XX, o sergipano João Ribeiro (1860-1934) publicou, em Portugal, suas Páginas de esthetica (Lisboa, Clássica, 1905). Poucos anos depois, Vicente Licinio (1890-1931) publicou sua Philosophia da arte (Synthese positiva e notas à margem): Arquitetura Americana. A margem das architecturas grega e romana $\left(1^{a}\right.$ ed., $1918 ; 2^{a}$ ed., Rio de Janeiro: J. Olympio, 1935). Cf. Machado, 1976.

Esses dados bibliográficos demonstram que, não muito tempo depois que as indagações sobre estética haviam se consolidado na Europa, já havia no Brasil algum interesse por esse campo filosófico. A partir desse período, pode-se falar de dois desenvolvimentos paralelos, que desembocaram numa situação propícia para a discussão sobre a cultura de massas na atualidade. Foram eles: 1) um aumento gradativo, porém constante, no interesse pela discussão de temas estéticos, no sentido tradicional e 2) o início, a partir da década de 1920, de atividades ligadas ao que ficaria depois conhecido como "cultura de massas" (ou, para falar com Horkheimer \& Adorno, "indústria cultural").

No que concerne ao primeiro desenvolvimento, depois dos supramencionados livros de estética publicados nas primeiras décadas do século $X X$, as reflexões sobre esse campo foram se beneficiando tanto de discussões sobre os rumos da arte em geral, como, por exemplo, aquela que se iniciou a partir da Semana de Arte Moderna de 1922 (sobre as reflexões estéticas de Mário de Andrade, ver Moraes, 1999), quanto - posteriormente - da consolidação paulatina dos departamentos de filosofia em universidades públicas de várias capitais brasileiras.

É claro que o desmantelamento dessas unidades acadêmicas pela ditadura militar depois do golpe de 1964 prejudicou muito não apenas o desenvolvimento da estética, como da filosofia em geral, no Brasil. Assim mesmo, nesse período despontaram no país estetas de primeira linha, como Benedito Nunes e Gerd Bornheim, assim como alguns passos importantes foram dados em termos institucionais, como, por exemplo, a criação, em 1971, 
do Laboratório de Estética da UFMG, pelo Professor Moacyr Laterza.

Já no que diz respeito ao desenvolvimento da cultura de massas no Brasil, o mesmo ano da Semana de Arte Moderna 1922 -, marcou a primeira transmissão de rádio no país, ainda em caráter experimental, nas comemorações do centenário da independência do país. Ao longo de toda a década de 1920 foram se formando rádio-clubes por todo o país e o advento do Estado Novo, depois da revolução de 1930, trouxe um enorme desenvolvimento nesse setor, depois que, em virtude de interesses ideológicos, Getúlio Vargas estatizou a Rádio Nacional, conferindo-lhe, por outro lado, autonomia para investir as receitas de publicidade no funcionamento da própria estação. Isso gerou uma situação de profissionalismo sem par no Brasil e talvez raramente encontrável em outras partes do mundo: em pouco tempo, a Rádio Nacional tinha excelentes equipamentos, cuja transmissão em ondas curtas atingia todo o país; tinha também os mais populares apresentadores, os melhores atores (e atrizes), os mais talentosos cantores (e cantoras), as melhores orquestras, os melhores grupos "regionais", etc.

Sua excelência funcionou como elemento indutor, tanto no mercado de radiodifusão quanto na indústria fonográfica, que desde o início do século XX também havia se desenvolvido continuamente. No início da década de 1950, quando as primeiras transmissões de televisão foram realizadas pela TV Tupi de São perder seu lugar de principal meio de comunicação de massa do Brasil, se encontrava totalmente estabelecido Paulo (seguidas pela criação de canais nas principais capitais brasileiras), o sistema de rádio, que estaria prestes a e difundido por todo o país.

Há que se mencionar uma peculiaridade da cultura de massas no Brasil, desde os seus primórdios: considerando-se que o cinema - diferentemente do rádio - não havia sido priorizado pelo poder público (talvez por ter repercussões ideológicas menos imediatas), ele se tornou, desde sua maior profissionalização na década de 1930, um medium complementar - para não dizer 
|84|

A estética e a discussão sobre indústria cultural no Brasil...

parasitário - com relação ao rádio. Sua função era mostrar, tanto nas cidades maiores quanto nos rincões mais distantes do país, como era a aparência das pessoas, cujas vozes eram já bastante familiares aos ouvintes: o cinema mostrava como os artistas do rádio eram "de verdade". Naturalmente, a televisão eliminou a necessidade dessa sinergia entre o rádio e o cinema e a transmissão em rede, via satélite, para todo país, iniciada pela TV Globo na década de 1970, lançou tanto o rádio quanto o cinema comerciais numa crise ainda mais profunda do que aquela em que eles já se encontravam desde o advento da televisão no Brasil, em 1950.

Essas informações, introduzidas quase aleatoriamente, já são suficientes para mostrar que a defasagem entre a consolidação da cultura de massas no Brasil, ainda que com um modelo bem próprio, foi de aproximadamente uma década e que, desde então, ela nunca parou de evoluir e de se adequar aos momentos político e tecnológico de suas congêneres nos países mais desenvolvidos. Um exemplo disso é o fato de que já há, desde alguns anos, transmissão de TV digital de alta definição nas capitais e grandes cidades do interior do país. Outro exemplo: considerando que também a Internet se tornou um medium importante da indústria cultural, é oportuno relembrar que o Brasil se encontra entre os países do mundo com maior número de conexões à web e perde para poucos outros em número de horas semanais de uso desse recurso. Por tudo isso, podemos dizer, sem medo de errar: yes, we do have culture industry.

Esse fato sugere que, assim como ocorreu na Europa e nos Estados Unidos no início do século XX certo giro da estética filosófica no sentido de tentar compreender criticamente os fenômenos da cultura de massa, não deixou de haver algo semelhante no Brasil, se bem que, talvez com um lapso de tempo maior do que o ocorrido na implantação da indústria cultural nesse país. Não que faltassem vozes isoladas que, desde o início dos anos 1960, destinassem pesadas críticas à cultura de massas no Brasil: há, por exemplo, os precoces impropérios de Vilém 
Flusser contra esse setor, em obras da primeira fase do seu pensamento, ${ }^{3}$ i.e., antes de ele se tornar um mundialmente reconhecido guru dos novos media.

De qualquer modo, talvez não seja errado dizer que as críticas mais pesadas e contundentes à indústria cultural no Brasil começaram a ocorrer exatamente no momento em que a Teoria Crítica da Sociedade - vertente fundada pelos supramencionados autores da Dialética do esclarecimento, Horkheimer \& Adorno - se consolidou no país. ${ }^{4} \mathrm{E}$ essa consolidação é um dos fenômenos mais interessantes da vida intelectual do país nas últimas décadas, já que, até o início da década de 1990, tinha havido apenas um "surto" de interesse - principalmente fora da academia - pela obra de Herbert Marcuse (outro representante da Teoria Crítica), nos anos 1960; na década seguinte, houve apropriações mais acadêmicas (principalmente na área de Letras) da obra de Walter Benjamin. Mas em nenhum dos dois casos houve ênfase na abordagem crítica da cultura de massas, ainda que as obras de ambos os filósofos comportasse tal enfoque.

A partir de 1990, o interesse foi se concentrando cada vez mais nos textos de Theodor Adorno, especialmente na sua estética, na qual se destaca exatamente a crítica à indústria cultural a partir de sua comparação com a "arte autônoma" do passado e com a arte de vanguarda do século XX. É oportuno observar que essas abordagens da estética de Adorno tiveram desde o início um caráter acadêmico, já que se manifestaram principalmente em forma de dissertações de mestrado, teses de doutorado, artigos de periódicos e livros (muitas vezes como adaptação do conteúdo de dissertações e teses).

A partir de um levantamento realizado há alguns anos, pode-se constatar que quase uma centena de trabalhos

\footnotetext{
${ }^{3}$ Por exemplo, em Lingua e realidade (primeiramente publicado em 1963) e A história do diabo (primeiramente publicado em 1965).

${ }^{4}$ Sobre a recepção da obra de Adorno no Brasil, ver Duarte, in Klein et alii, 2011, p. 471 ss.
} 
$|86|$

A estética e a discussão sobre indústria cultural no Brasil...

acadêmicos sobre Theodor Adorno (aproximadamente $1 / 3$ de teses de doutorado e $2 / 3$ de dissertações de mestrado) havia sido defendida no Brasil desde o início da década de 1990. Desse montante, algumas dezenas tinham sido publicados em forma de livro, adquirindo, assim maior capacidade de circulação e, portanto, de divulgação das ideias desse autor. Outro número expressivo: quase duas centenas de artigos havia sido publicada em periódicos desde então, sendo que, a exemplo dos outros trabalhos acadêmicos realizados, uma parte expressiva deles ou abordava a estética de Adorno, num sentido mais amplo, ou se destinava diretamente à discussão do tema da indústria cultural, sob os pontos de vista mais diversos: filosófico, sociológico, pedagógico, etc.

É interessante observar que, embora não tenha havido debates em que posições específicas tenham sido defendidas, desde meados da década de 1990 têm ocorrido eventos em que o tema da indústria cultural assume papel de destaque nas discussões, tais como os de Belo Horizonte (agora realizados também em Ouro Preto) e os realizados pelo Grupo de Pesquisa Teoria Crítica e Educação, sediado na UNIMEP (mas com eventos ocorridos não apenas em Piracicaba, mas também em outras cidades do interior paulista). Uma provável causa da peculiaridade desse tipo de discussão é que parece não haver a possibilidade de um autêntico debate entre os adeptos da concepção de indústria cultural e os seus críticos mais ferrenhos, ${ }^{5}$ uma vez que já os pontos de partida são totalmente heterogêneos e não geram a oportunidade de um debate construtivo. Desse modo, os ganhos de conhecimento que têm sido obtidos sobre a indústria cultural, seja no seu modelo mais "globalizado" ou na sua versão brasileira, dizem respeito à elucidação de aspectos menos evidentes de seu funcionamento, de seus efeitos nas consciências, de suas estratégias sempre renovadas, etc. Uma

\footnotetext{
${ }^{5}$ Um exemplo dessa posição ferrenhamente contrária até mesmo à concepção de indústria cultural pode ser encontrado em Puterman, 1994.
} 
vez que os resultados desse debate têm sido publicado em artigos, livros e volumes de anais relativos aos eventos em que eles ocorrem (ver seleção bibliográfica a seguir), pode-se dizer que ele não está de modo algum fechado e deve ser continuado, tendo em vista a recepção, presente e futura, do material já publicado e que ainda está por ser publicado.

Bibliografia selecionada (títulos brasileiros sobre indústria cultural e temas afins)

ALBERTI DA ROSA, R. Música e Mitologia do Cinema - Nas trilhas de Adorno e Eisler. Ijuí: Editora Unijuí, 136 p. 2003.

Catarse e Resistência - Adorno e os limites da obra de arte crítica na Pós-modernidade. Canoas: Editora da ULBRA, 208 p. 2008.

ALBINO, B. S. e VAZ, A. F. “Corpo, vida, diagnóstico do presente: Aproximações exploratórias entre Theodor W. Adorno e Michel Foucault". Lecturas: Educación Física y Deportes, v. 13, pp. 1-9. 2008.

ALMEIDA, J. M. B. de. Theodor W. Adorno. Indústria cultural e sociedade. $1^{\text {a }}$ ed. São Paulo: Paz e Terra, 127 p. 2002.

ALVES JÚNIOR, D. G. "Adorno e a questão da indústria cultural: O que está em jogo?". Caderno de Educação, Belo Horizonte, v. 1, n. 1, pp. 56-61. 2001.

ARGUELHES, D. de O. e DOMINGOS, M. J. “Jazz, rock'n'roll, música pop, regressão da audição e fetichismo na música: Alguns apontamentos sobre um velho texto de Theodor W. Adorno". Universitas. História. UNICEUB, v. 1, pp. 89-115. 2001.

BAHIA, R. J. B. Das luzes à desilusão: O conceito de indústria cultural em Adorno e Horkheimer. Belo Horizonte: Autêntica; FHCFUMEC, 2004. 
$\mid 88$ |

A estética e a discussão sobre indústria cultural no Brasil...

BASSANI, J. J. e VAZ, A. F. “Técnica, corpo e coisificação: Notas de trabalho sobre o tema da técnica em Theodor W. Adorno". Educação e Sociedade, v. 29, pp. 99-118. 2008.

BUENO, S. F. Educação, paranoia e semiformação. Educ. rev. [online], v. 26, n. 2, pp. 299-315. 2010.

BURNETT, H. “Adorno (e sempre) o jazz". Letras: Periódico cultural, Belo Horizonte, p. 7, jul. 2008.

"Mário de Andrade visita Adorno". Trópico: Idéias de norte a sul, 15 out. 2007.

CARONE, I. "Adorno e a educação musical pelo rádio". Educação e Sociedade, Universidade de Campinas, v. 24, n. 83, pp. 30-43. 2003.

COHN, G. "Difícil reconciliação: Adorno e a dialética da cultura". Lua Nova. Revista de Cultura e Política, São Paulo, n. 20, pp. 5-18. 1990.

DUARTE, R. A. P. Adorno/Horkheimer \& a Dialética do esclarecimento. Rio de Janeiro: Jorge Zahar Editor, v. 1, 72 p. 2002.

DUARTE, R. A. P.; FIGUEIREDO, Virginia de Araújo e KANGUSSU, Imaculada. Theoria Aesthetica. Em comemoração ao centenário de Theodor W. Adorno. $1^{\text {a }}$ ed. Porto Alegre: Escritos Editora, v. 1. 381 p. 2005.

DUARTE, R. Teoria crítica da indústria cultural. Belo Horizonte: Editora UFMG, 2003.

. Indústria cultural: Uma introdução. Rio de Janeiro: Editora FGV, 2010.

DUARTE, R. et alii (orgs.). Kátharsis. Reflexões sobre um conceito estético. Belo Horizonte: Editora C/Arte, 2002.

DURÃO, F. A. (org.). Culture Industry today. Cambridge Scholars Publishing, 2010. 
DURÃO, F. A.; ZUIN, Antônio e VAZ, Alexandre Fernandez (org.). A indústria cultural hoje. São Paulo: Boitempo Editorial, 2008.

FABIANO, L. H. "Adorno, Arte e Educação: Negócio da arte como negação". Educação e Sociedade, Campinas, v. 24, n. 83, pp. 495-505. 2003.

FREITAS, V. Adorno e a arte contemporânea. Rio de Janeiro: Jorge Zahar, 72 p. 2003.

. "Theoria Aesthetica de Theodor Adorno". Revista Portuguesa de Filosofia, Braga, v. 60, n. 1, pp. 253-255, 2004.

GATTI, L. F. Constelações. Crítica e verdade em Benjamin e Adorno. São Paulo: Edições Loyola, 2009.

LOUREIRO, R. "Considerações sobre o cinema na teoria crítica - Theodor Adorno e Alexander Kluge: Um diálogo possível". Impulso, Pircacicaba, n. 39, pp. 1-18. 2005.

"Considerações sobre a filosofia de Theodor Adorno e o pós-moderno". Educação e Realidade, v. 34, pp. 175-190, 2009.

MAAR, W. L. "Adorno, Semiformação e Educação". Educação e Sociedade, Campinas, v. 24, n. 83, pp. 459-475, 2003.

"Política e Sujeição Social pela Forma em Adorno". Textos-Instituto de Pesquisas Sociais - Escola de Frankfurt. São Paulo, 2006.

MARCONDES FILHO, C. J. R. “Theodor Adorno: A crise da crítica da comunicação". Hypnos. São Paulo, v. 19, pp. 45-67, 2007.

NASCIMENTO, B. R. "A mistificação das massas: os operadores da indústria cultural na obra de Adorno e Horkheimer". Revista Temática. Ano VII, n. 9. pp. 1-16, set. 2011. 
$|90|$

A estética e a discussão sobre indústria cultural no Brasil...

NOBRE, M. "Objeções marxistas? Adorno e Benjamin na 'encruzilhada de magia e positivismo" dos anos 30. Cadernos de Filosofia Alemã, São Paulo, v. 3, pp. 45-59, 1997.

PAGNI, P. A. "O filosofar na arte de educar entre o corpo e a infância: Considerações a partir de Adorno e Lyotard". Childhood E Philosophy, Montclair, USA/ Rio de Janeiro, v. 1, n. 1, p. 3. 2005.

"O problema do corpo na educação contemporânea: paralelos entre Foucault e Adorno". Itinerários de Filosofia da Educação, v. 4, pp. 175-192. 2006.

"Dimensão Estética, linguagem e comunicação na experiência educativa: Divergências entre Dewey e Adorno". Educação e Filosofia. UFU. Impresso, v. 23, pp. 169-188. 2009.

PUCCI, B. "Filosofia negativa e Educação: Adorno". Filosofia, Sociedade e Educação, UNESP - Marília, v. 1, n. 1, pp. 163-192. 1997.

. Anais do Colóquio Nacional "O Ético, o Estético, Adorno". São Paulo: Gráfica da UNIMEP, 57 p. 1998.

RAMOS, C. “O ressentimento do guerreiro: Reflexões sobre corpo e educação a partir do pensamento de Theodor Adorno e da Psicanálise". Interações. Universidade São Marcos, v. XI, pp. 9-28. 2006.

. "Consumismo e gozo: Uma compreensão de ideologia entre T.W. Adorno e J. Lacan”. Psicologia USP, v. 19, pp. 199212. 2008.

RAMOS-DE-OLIVEIRA, N.; ZUIN, A. A. e PUCCI, B. T.W. Adorno: O Poder Formativo do Pensamento Crítico. Petrópolis: Vozes, 140 p. 2001.

RÜDIGER, F. “Revolvendo a dialética negativa: Arte e indústria cultural em Adorno". Comunicarte, v. 22, pp. 46-58. 1998a. 
“Técnica, arte e indústria cultural segundo Adorno". Veritas. Porto Alegre, v. 43, pp. 339-411. 1998b.

. Theodor Adorno e a crítica à indústria cultural. Porto Alegre: Edipucrs, 288 p. 2004.

SILVA, P. L. "Sobre educação, cultura e humanidade em Adorno". Trilhas Filosóficas, v. 1, pp. 9-25. 2009.

SILVA, R. C. "A atualidade da crítica de Adorno à indústria cultural". Educação e Filosofia, Uberlândia, v. 13, n. 25, pp. 27-42. 1999.

SOARES, J. C. e EWALD, A. P. "Reflexões à sombra de Adorno: Cultura do consumo, vazio existencial e sofrimento psíquico". Nómadas, Madri, v. 1, n. 1, pp. 1-12. 2004.

TIBURI, M. A. “Notas e esboços da dialética do esclarecimento de Theodor Adorno e Max Horkheimer". Cadernos IHU Idéias, Unisinos, São Leopoldo, v. 4, n. 1, pp. 31-47. 2003.

VASCONCELLOS, J. L. R. "Adorno, a música e o cinema". Trama. UERJ, Rio de Janeiro, n. 4, pp. 12-20. 1994.

VAZ, A. F. "Razão e corporeidade: elementos para a compreensão do corpo na modernidade". Revista Brasileira de Ciências do Esporte, Florianópolis, v. 17, n. 2, p. 202. 1996.

. "Dominar a natureza, educar o corpo: notas a partir do tema da mímesis em Theodor W. Adorno e Max Horkheimer". Lecturas Educación Física y Deportes, Buenos Aires, Argentina, v. 5, n. 27. 2000a.

"Na constelação da destrutividade: o tema do esporte em Theodor W. Adorno e Max Horkheimer". Motus Corporis. UGF, Rio de Janiero, v. 7, n. 1, pp. 65-108. 2000b.

. "Esporte e indústria cultural em Theodor W. Adorno: Reflexões sobre a educação do corpo". Nuances, Presidente Prudente, v. VIII, n. 8, pp. 33-46. 2002. 
. "Corporalidade e Formação na Obra de Theodor W. Adorno: Questões para a reflexão crítica e para as práticas corporais". Perspectiva, Florianópolis, v. 22, n. Especial, pp. 21-49. 2004.

VON BAUMGARTEN, Alexander. Estética. A lógica da arte e do poema. Petrópolis: Vozes. 1993.

ZUIN, A. A. S. "Educação e emancipação: Adorno, crítico da semicultura". Pro-Posições. Unicamp, Campinas, v. 8, n. 2, pp. 71-83. 2000.

\section{Bibliografia}

DUARTE, R. "Brasilien". In: KLEIN, Richard et alii. Adorno Handbuch. Leben-Werk-Wirkung. Stuttgart: J. B. Metzler, p. 471 ss. 2011.

HORKHEIMER, Max e ADORNO, T. Dialektik der Aufklärung. Frankfurt am Main: Suhrkamp, p. 181 ss. 1981.

. Dialética do esclarecimento. Tradução: Guido Almeida. Rio de Janeiro: Jorge Zahar, p. 148. 1985.

KANT, I. Kritik der Urteilskraft. Frankfurt am Main: Suhrkamp, p. 115. 1984.

. Crítica da faculdade do juízo. Tradução: Valério Rohden e António Marques. $2^{\text {a }}$ ed. Rio de Janeiro: Forense Universitária. 1995.

MACHADO, G. P. A filosofia no Brasil. $3^{\text {a }}$ ed. acrescida de notas. São Paulo: Cortez e Moraes. 1976.

MORAES, E. J. de. Limites do moderno. O pensamento estético de Mario de Andrade. Rio de Janeiro: Relume Dumará. 1999.

NIETZSCHE, F. “Genealogie der Moral”. In: Werke III. Frankfurt am Main/Berlim/Viena: Ulstein, p. 317. 1979. 
PUTERMAN, P. Indústria cultural: A agonia de um conceito. São Paulo: Perspectiva. 1994. 